(C) Elsevier/INRA

Original article

\title{
Optimization of selection response under restricted inbreeding
}

\author{
iM Toro*, M Pérez-Enciso \\ Universidad Complutense, Facultad de Biología, Departamento de Genética, \\ 28040 Madrid, Spain
}

(Received 4 January 1989; accepted 13 September 1989)

\begin{abstract}
Summary - A reasonable objective for selection programs in small populations is the maximization of response, with a restriction on the increase of inbreeding. This restriction will be especially important when information on relatives is used for evaluation of candidates for selection. To achieve this objective, different strategies have been proposed: (i) to reduce the intensity of selection; (ii) to lower the weight given to family information in an index below the optimal value; (iii) to restrict the variation of family size, (iv) to make matings between the selected animals, so as to minimize the average coancestry coefficient; and $(v)$ to find a general solution using linear programing. These strategies have been illustrated by genetic simulation of a simple example. The population consisted of 8 males and 8 females selected from 32 animals evaluated in each sex. The candidates were evaluated by an index using information on the individual and its 7 sibs. Five generations of selection were practised. It was concluded that there are several alternative strategies which ensure that inbreeding is below the fixed level (5\% per generation) without a significant loss of response, in comparison with classical strategies, where inbreeding is not restricted. A substantial reduction of inbreeding was found with the use of matings having minimal coancestry. However, this reduction was due principally to a delay of 1 generation in the appearance of inbreeding. Linear programing was also efficient in achieving these aims. It is, in principle, more flexible than the other strategies, but its heavy cost of computation is a disadvantage, and, in practice, comparable results can probably be obtained using much simpler strategies.
\end{abstract}

effective size / artificial selection / linear programing / computer simulation / inbreeding

Résumé - Optimisation de la réponse à la sélection avec une restriction sur la consanguinité - Une proposition raisonnable dans les programmes de sélection en petits troupeaux est la maximisation de la réponse avec une restriction sur l'augmentation de la consanguinité. Cette restriction sera spécialement importante quand l'information sur les parents est considérée pour l'évaluation des candidats. Pour arriver à cet objectif, différentes méthodes ont été proposées: (i) réduire l'intensité de la sélection; (ii) ramener le poids de l'information sur les parents en dessous de la valeur optimale dans. un indice familial; (iii) restreindre la distribution des tailles de famille; (iv) réaliser des accouplements entre les animaux sélectionnés avec un coefficient de parenté minimal; et (v) appliquer une solution générale avec l'utilisation de la programmation linéaire. Ces

* Correspondence and reprints 
méthodes ont été illustrées par des simulations génétiques sur un exemple. La population était formée de 8 mâles et 8 femelles sélectionnés parmi 32 animaux évalués dans chaque sexe. Les candidats ont été évalués selon un indice comprenant l'information sur l'individu et ses 7 frères. Cinq générations de sélection ont été réalisées. On est arrivé à la conclusion qu'il existe plusieurs méthodes alternatives qui assurent une consanguinité en dessous de la valeur fixée (5\% par génération) sans perte significative de la réponse en comparaison avec les méthodes classiques, où la consanguinité n'est pas restreinte. On a trouvé une réduction substantielle de la consanguinité avec des accouplements de parenté minimale. Cependant cette réduction a été due principalement au retard d'une génération dans l'apparition de la consanguinité. La programmation linéaire a été efficace également pour arriver à ces fins. Elle est, en principe, plus flexible que les autres méthodes, mais son coût important de calcul est un inconvénient, et, dans la pratique, des résultats similaires peuvent être probablement obtenus avec des méthodes beaucoup plus simples.

effectif génétique / réponse à la sélection / programmation linéaire / simulation aléatoire / consanguinité

\section{INTRODUCTION}

The total number of individuals under control in an animal breeding program is usually constrained by economic factors. The choice of effective population size depends mainly on fertility and fecundity parameters, as well as on predictions of response to selection. Of all the variables an animal breeder can manipulate, population size is the one that has the widest range of consequences. In the short term, it influences the selection differential, the inbreeding depression and the reduction of genetic variance due to genetic drift. In the long term, it affects the selection limit and the utilization of a new variation arising from mutation (see Hill, 1986, for a review).

Furthermore, in a population under artificial selection, the effective population size will be lower than that expected in a random-mating control population of equal size because parents do not have an equal chance of contributing offspring to the next generation, even if all pairs of parents contribute an equal number of progeny to be measured (Robertson, 1961). Moreover, the efficient use of family information by selection indices or BLUP methodology will lead to more individuals from the best families being selected and, therefore, considerable reductions of population size will follow.

Some problems related to the optimization of response in selection programs in populations of finite size have been explored by Robertson $(1960 ; 1970)$. Using the infinitesimal model for the decay of genetic variability, he showed that if individual selection is carried out from a constant number $2 M$ of individuals scored per generation, the maximum advance at the limit is achieved when the best half is selected. He also showed that the proportion selected to give the maximum cumulated gain after $t$ generations is a function of $t / 2 M$. Experimental checks on the theory have been reported by Ruano et al (1975) and Frankham (1977).

Dempfle (1975) investigated the effect of within-family selection on selection limits, showing that this method is more efficient than individual selection when the heritability is very high, because of a relatively lower decay of the additive variance during selection. This prediction was experimentally checked by Gallego and Lopez-Fanjul (1983) and Butler et al (1984). In parallel, Toro and Nieto (1984) 
have proposed a simple method, called weighted selection, that also leads to higher selection limits.

A different approach focuses attention on inbreeding depression, and several methods have been proposed to minimize the rate of inbreeding in selection programs; $i e$, by reducing selection intensity, by ignoring some family information, or by imposing restrictions on family size, such as practising within-sire selection. Other methods, such as minimum coancestry mating, may also be advisable (Toro et al, 1988a).

The purpose of this work is to analyse the above methodologies and to discuss some aspects of optimization of genetic progress when the acceptable level of inbreeding is fixed a priori. Although there are other possible approaches, such as maximizing cumulated selection gain in a given period of time, the approach taken here is perhaps a more realistic one as, in practice, breeders choose an empirical level of inbreeding such that the selected or reproductive traits will not be impaired by an excess of consanguinity (Smith, 1969; Land, 1985).

These methodologies will be illustrated with a simple computer simulation example.

\section{Strategies of optimization in selection with restricted inbreeding}

A selection program consists of 2 main steps: (1) ranking and choice of candidates; (2) mating of selected animals. To attain the objective outlined above, these 2 aspects can either be considered separately or jointly. The first 3 strategies analysed in this paper refer to step 1, the 4th to step 2 exclusively, while in the 5th strategy, a general solution combining both steps is sought.

The breeding structure considered here is a closed population with $k$ families, each family contributing $n$ males and $n$ females as candidates for selection, and $k$ individuals are selected out of the $M=k n$ eligible from each sex. In all strategies, selection is based on a family linear index of the form:

$$
I=(P-F)+\lambda(F-\bar{P})
$$

where $P, F$ and $\bar{P}$ are the individual's own performance, its family mean and the population mean, respectively, and $\lambda$ is the weight given to family information.

\section{Optimal selected proportion}

The choice of an adequate proportion of selected individuals is the simplest way of diminishing the level of inbreeding and it will not be discussed further. However, it should be pointed out that the range of choice is limited if a balanced family structure is to be maintained.

\section{Optimal weight given to family information}

The second alternative that can be considered is to ignore some family information or, more strictly, to reduce the relative importance given to the family mean below the value that maximizes the correlation between the index and breeding value. As $\lambda$ decreases, the intrafamily (intraclass) correlation of index decreases (see eqn(2) below) and, consequently, the effective population size will increase. 


\section{Restriction on the distribution of family size}

The third strategy that can be utilized to maintain a desired rate of inbreeding is to impose some constraints on the number of selected individuals contributed by different families, such as practising some kind of within-family selection with respect to the index. Given a fixed number of families, with within-family selection, the variance of family size is zero and the effective population size is maximum, while with family selection, the rate of inbreeding and the variance of family size will be maximum. Nevertheless, there is a wide range of intermediate selection methods which differ in the magnitude of the variance of family size that can be imposed and, apparently, this possibility has commonly been overlooked. All possible distributions of family size are equivalent to all the possible forms of arranging $k$ marbles (the selected individuals) among $k$ boxes (families), each of capacity $n$ (maximum family size). These arrangements will follow a multi-hypergeometric distribution.

\section{Minimum coancestry matings}

Following a different approach, Toro et al (1988a) have emphasized the utility of 2 methods to minimize inbreeding in selection programs. The first is minimum coancestry mating (MC), where matings are chosen to minimize average pairwise coancestry coefficients between males and females in the selected group. The second is a method proposed by Toro and Nieto (1984), which is called "weighted selection" and is fully explained in the article. Both methods were evaluated (Toro et al, (1988a) by computer simulation and it was concluded that the first is the most promising in the short term and, therefore, it will be the only one considered here.

\section{Mate selection; a general solution for the maximization of genetic progress under restricted inbreeding}

It is desirable to have a general solution that could incorporate the main features of the methods previously described. Such a solution can be obtained by means of linear programing techniques. If $k$ males and $k$ females are to be selected out of $M$ available from each sex, we must choose the best $k$ pairs among the $k !\left[\begin{array}{c}M \\ k\end{array}\right]\left[\begin{array}{c}M \\ k\end{array}\right]$ possible mating combinations; "best" meaning that we seek to maximize genetic progress while maintaining the rate of inbreeding below a certain value.

The problem can be solved using integer linear programing algorithms which is reduced to find a $\mathbf{X}=\left[x_{i j}\right](i, j=1, M)$ matrix, where $x_{i j}$ represents a decision variable indicating whether the $i^{\text {th }}$ male and the $j^{\text {th }}$ female are $\left(x_{i j}=1\right)$ or are not $\left(x_{i j}=0\right)$ to be selected and mated. Such a matrix is chosen to maximize the expected genetic progress:

$$
z=\frac{1}{2 k} \sum_{i j}^{M} x_{i j}\left(\widehat{a}_{i}+\widehat{a}_{i}\right)-\frac{1}{2 M} \sum_{i j}^{M}\left(\widehat{a}_{i}+\widehat{a}_{j}\right)
$$

where $\widehat{a}_{i}$ and $\widehat{a}_{j}$ are the best available estimates of the breeding values of the $i^{\text {th }}$ sire and the $j^{\text {th }}$ dam, respectively, subject to the following restrictions: 
(i) $x_{i j}=0$ or 1 (for all values of $i, j$ )

(ii) $\sum_{i j}^{M} x_{i j}=k$

(iii) $\sum_{i}^{M} x_{i j} \leq 1$ (for all values of $j$ )

(iv) $\sum_{j}^{M} x_{i j} \leq 1$ (for all values of $i$ )

(v) $\sum_{i j}^{M} x_{i j} f_{i j} / k \leq F+\Delta F$

where $F, \Delta F$ and $f_{i j}$ are, respectively, the population mean inbreeding coefficient in generation $t$, the maximum rate of increase permitted, and the coancestry coefficient between the $i^{\text {th }}$ male and the $j^{\text {th }}$ female. Restrictions (iii) and (iv) simply indicate that a male or a female will be mated only once at maximum, ie, there are no half-sibs.

\section{METHODS}

\section{Prediction of selection response and inbreeding}

The value of $\lambda$ that maximizes correlation between value and index score, assuming an infinite population, is:

$$
\lambda_{o p}=\frac{(1-\rho)(1-r+2 r n)}{(1-r)(1-\rho+2 \rho n)}
$$

where $r=0.50$ for full-sib families, and $\rho$ is the intraclass phenotypic correlation.

The selection intensity for finite populations under selection was obtained from the tables in Hill (1976), using the appropriate intrafamily (intraclass) correlation of the index, $\rho_{I}$, given by

$$
\rho_{I}=\frac{\left(\lambda^{2}+1\right)(\rho+(1-\rho) / 2 n+\rho)}{\left(\lambda^{2}+1\right)(\rho+(1-\rho) / 2 n+1)}
$$

Expected responses were obtained from standard methods (Falconer, 1981), and $N_{e}$ from Burrow's (1984) formula, that is strictly valid only for 1 generation,

$$
N_{e}=\frac{2(2 M-1)}{2 n-1} R\left(\alpha, \rho_{I}\right)
$$

and

$$
R\left(\alpha, \rho_{I}\right)=\left[1+\left(F_{2}\left(x_{\alpha}, \rho_{I}\right)-\left(1-\alpha^{2}\right)\right)(k-1) / k \alpha^{2}\right]^{-1}
$$

where $\alpha$ is the proportion selected, and $F_{2}\left(x_{\alpha}, \rho_{I}\right)$ is the conditional probability that 2 standardized normal variables with correlation $\rho_{I}$ do not exceed the truncation point, $x_{\alpha}$. The probabilities were obtained from the tables in Gupta (1963), but 
can also be computed by the numerical integration methods described in Ducrocq and Colleau (1986).

Expected $F$ values for generation $t$ were obtained using Crow and Kimura's (1970) formula

$$
F_{t}=\frac{1}{2 N_{e}}\left(1+F_{t-2}\right)+\frac{N_{e}-1}{N_{e}} F_{t-1}
$$

In the case of fixed family size ( $3^{\text {rd }}$ strategy), selection response can be approximately predicted by assuming that selection has occurred in 2 distinct steps. First, families are ranked according to their mean index values, the best family(ies) are selected and, in a second step, the best individual(s) from each family is(are) selected according to their previously fixed contribution. Since the between- and withinfamily components are uncorrelated, the total response $(R)$ can be split up into 2 parts, those due to family $\left(R_{f}\right)$ and within-family $\left(R_{w}\right)$ selection, respectively. Thus, if we denote by $c_{i}$, the number of selected individuals of each sex contributed by the $i^{\text {th }}$ family $\left(0 \leq c_{i} \leq n\right)$

$$
R=R_{f}+R_{w}=i_{f} h_{f}^{2} \sigma_{f}+i_{w} h_{w}^{2} \sigma_{w}
$$

where $\sigma$ is the standard deviation, as defined in Falconer (1981), and subscripts $f$ and $w$ refer to family and within family, respectively. The intensities of selection, $i_{f}$ and $i_{w}$, are

$$
\begin{aligned}
& i_{f}=\sum_{i=1}^{k} S_{i} c_{i} / k=\frac{1}{k} \sum_{i=1}^{k} S_{i} c_{i} \\
& i_{w}=\sum_{i=1}^{k} \frac{c_{i}}{k} \sum_{j=1}^{c_{i}} S_{j}^{\prime} / c_{i}=\frac{1}{k} \sum_{i=1}^{k} \sum_{j=1}^{c_{i}} S_{j}^{\prime}
\end{aligned}
$$

where $S_{i}$ is the $i^{\text {th }}$ order statistic from $k$ independent normal variables and $S_{j}^{\prime}$ is the $j^{\text {th }}$ order statistic from an $n$-dimensional normal distribution with correlation equal to $-1 /(n-1)$, obtained from Owen (1962) and Owen and Steck (1962).

The effective population size for a constant distribution of family size was obtained from Crow and Denniston's (1988) formula,

$$
N_{e}=\frac{8 k-4}{2+\sigma_{k}^{2}}
$$

where $\sigma_{k}^{2}$ is the variance of family size.

\section{Simulation methods}

In the genetic simulations, the trait was assumed to be controlled by 100 biallelic additive loci, with equal effects and initial frequencies, spaced with recombination rates of 0.50 . The genotypic (additive) values per locus were 4,3 and 2 for the AA, Aa and aa allelic combinations, respectively. The initial frequency of the A allele was 0.50 , implying an additive genetic variance $\sigma_{A}^{2}=50$. Phenotypic values were obtained simply by adding a random normal deviate of variance $\sigma_{E}^{2}$ to the genotypic 
values, corresponding to heritabilities of $0.10\left(\sigma_{E}^{2}=450\right)$ and $0.30\left(\sigma_{E}^{2}=116.66\right)$, respectively. Genetic values were independent of environmental effects.

In the example considered, the number of families, $k$, was 8 , with $n=4$ individuals of each sex per family. Five generations of selection were performed and the desirable maximum rate of inbreeding imposed was $5 \%$ per generation.

The performance of the linear programing strategy was carried out introducing the MIF integer programing subroutines (Land and Powell, 1973) in the genetic simulation program. In order to simplify the problem, the best 16 males and the 16 best females (out of the 32 eligible) were considered. This was done to facilitate computing, but it is intuitively appealing since, in practice, as suggested by Smith (1969), it would be better to use unscored individuals, than individuals which are below average. The number of runs was 400 , except in the integer programing method in which, in order to save computing time, 50 replicates were run.

\section{RESULTS}

\section{Optimal weight given to family information}

Table I presents the theoretically predicted genetic progress $\left(R_{E}\right)$ and the inbreeding coefficient $\left(F_{E}\right)$ attained after 5 ,generations of selection, for different values of $\lambda$ and the 2 values of heritability considered $\left(h^{z}=0.10\right.$ and 0.30$)$. Notice that $\lambda=0$ means unrestricted within family selection; $i e$, that an individual is selected solely according to its deviation from family mean, and thus, each family can contribute between 0 and $\min (n, k)$ individuals (Dempfle, 1988), and $\lambda=1$ phenotypic individual selection. Optimum $\lambda$ values obtained from eqn(1) are also included in the lower row of the Table. It is interesting to notice that the relationship between $R_{E}$ and $\lambda$ follows a law of diminishing returns; $i e$, a change in $\lambda$ from 0 to 1 , or from 1 to 2 , results in an important increase in response, whereas, a change from 3 to 4 results in practically no progress, and, more importantly, further increments in $\lambda$ are even expected to reduce response. This is because, as $\lambda$ gets larger, the increasing correlation between the index and breeding value is overcompensated by the reduction in the intensity of selection and, consequently, $\lambda_{o p}$ does not give the maximum response. In parallel, expected inbreeding coefficients $\left(F_{E}\right)$, computed from eqn(4), steadily increase with $\lambda$. Considering jointly $R_{E}$ and $F_{E}$ values, it can be seen that values of $\lambda=3\left(h^{2}=0.10\right)$ and $\lambda=2.5\left(h^{2}=0.30\right)$ should be chosen in order to restrict the increment in inbreeding below $5 \%$ per generation.

The above prediction for $F_{E}$ is strictly valid for only 1 generation and applies solely to neutral genes which affect neither fitness nor the trait under selection, and which are not linked to genes affected by selection. In successive generations, there will be a cumulative effect on the variance of family sizes up to a limiting factor of 4 (Robertson, 1961) but, at the same time, there will be a reduction in the genetic variance and changes in other parameters such as $\rho_{I}$ acting in the opposite direction. In order to check the adjustement of the predictions, genetic simulations were performed. The results, $R_{o}$ and $F_{o}$, also appear in Table I. In general, disagreement between observed and expected values for both response and inbreeding becomes larger as $\lambda$ increases. This should be taken into account when predictions on possible advantages of using family information are made (Toro et al, 1988b). However, they 
Table I. Expected and observed cumulative selection response, $R_{E}$ and $R_{o}$, and inbreeding coefficient (\%), $F_{E}$ and $F_{o}$, after 5 generations of selection, as a function of the weight given to family information, $\lambda$. The initial additive variance was 50 .

\begin{tabular}{llrrrr}
\hline & $\lambda$ & $R_{E}$ & $R_{o}$ & $F_{E}$ & $F_{o}$ \\
\hline$h^{2}=0.10$ & 0 & 6.64 & 6.26 & 12.86 & 10.65 \\
& 1 & 13.80 & 11.74 & 13.63 & 14.65 \\
& 2 & 17.22 & 13.79 & 19.32 & 21.45 \\
& 3 & 18.45 & 15.27 & 23.81 & 26.28 \\
& 4 & 18.80 & 14.97 & 26.87 & 30.03 \\
& 5 & 18.88 & 14.89 & 28.98 & 32.39 \\
& 6 & 18.85 & 14.88 & 30.48 & 34.37 \\
$h^{2}=0.30$ & 7 & 18.77 & 14.46 & 31.55 & 35.06 \\
& 6.33 & 18.83 & 15.00 & 30.85 & 34.52 \\
& & & & & \\
& 0.0 & 12.16 & 11.81 & 12.86 & 10.06 \\
& 1.0 & 23.72 & 16.87 & 15.38 & 12.97 \\
& 1.5 & 26.14 & 19.62 & 19.08 & 17.22 \\
& 2.0 & 27.27 & 21.62 & 22.24 & 25.06 \\
& 2.5 & 27.65 & 21.50 & 24.71 & 26.90 \\
& 3.0 & 27.73 & 21.73 & 26.64 & 29.06 \\
& 3.5 & 27.68 & 21.70 & 28.14 & 30.08 \\
& 4.0 & 27.57 & 21.36 & 29.36 & 31.94 \\
& 3.73 & 27.64 & 21.09 & 28.71 & 31.92 \\
\hline
\end{tabular}

Standard errors ranged from 0.24 to $0.28\left(R_{o}\right)$, and from 0.16 to $0.43\left(F_{o}\right)$.

confirm expectations in the sense that the largest response was obtained with a $\lambda$ value below the optimum in infinite populations (eqn(1)). Since inbreeding was larger than expected, and differences between observed responses for $\lambda>1$ were small, perhaps in practice, a value of $\lambda=2$ should be chosen for both heritabilities.

\section{Restriction on the distribution of family size}

In the example, there are as many as 15 different distributions of family size, and they are shown in Table II. Case 1 corresponds to family selection (with respect to the index), in which the best families for each sex were selected, each contributing 4 individuals. In case 2 , families were ranked according to their 4 individual means for each sex, and the 4 full-sibs belonging to the best family were selected. Then, the remaining families were ranked again by the means of their best 3 individuals and the 3 individuals from the best family were selected. Finally, the best individual from a remaining family was chosen. The same logic applies to the following cases. Case 15 is obviously the well-known within-family selection, with respect to the index. For the sake of comparison, the optimum combined selection method is included in the last row of the Tables. 
Table II. Expected and observed cumulative selection response, $R_{E}$ and $R_{o}$, and inbreeding coefficient (\%), $F_{E}$ and $F_{o}$, after 5 generations of selection, as a function of family size. The initial additive variance was $50, h^{2}=0.10$.

\begin{tabular}{|c|c|c|c|c|c|}
\hline Case & $\begin{array}{l}\text { Distribution of } \\
\text { family size }\end{array}$ & $R_{E}$ & $R_{o}$ & $F_{E}$ & $F_{o}$ \\
\hline $\begin{array}{l}1 \\
2 \\
3 \\
4 \\
5 \\
6 \\
7 \\
8 \\
9 \\
10 \\
11 \\
12 \\
13 \\
14 \\
15 \\
\text { Opt. }\end{array}$ & $\begin{array}{llllllll}4 & 4 & 0 & 0 & 0 & 0 & 0 & 0 \\
4 & 3 & 1 & 0 & 0 & 0 & 0 & 0 \\
4 & 2 & 2 & 0 & 0 & 0 & 0 & 0 \\
4 & 2 & 1 & 1 & 0 & 0 & 0 & 0 \\
3 & 3 & 2 & 0 & 0 & 0 & 0 & 0 \\
3 & 3 & 1 & 1 & 0 & 0 & 0 & 0 \\
4 & 1 & 1 & 1 & 1 & 0 & 0 & 0 \\
3 & 2 & 2 & 1 & 0 & 0 & 0 & 0 \\
3 & 2 & 1 & 1 & 1 & 0 & 0 & 0 \\
2 & 2 & 2 & 2 & 0 & 0 & 0 & 0 \\
2 & 2 & 2 & 1 & 1 & 0 & 0 & 0 \\
3 & 1 & 1 & 1 & 1 & 1 & 0 & 0 \\
2 & 2 & 1 & 1 & 1 & 1 & 0 & 0 \\
2 & 1 & 1 & 1 & 1 & 1 & 1 & 0 \\
1 & 1 & 1 & 1 & 1 & 1 & 1 & 1\end{array}$ & $\begin{array}{r}17.42 \\
18.17 \\
17.87 \\
17.78 \\
17.30 \\
17.21 \\
16.38 \\
16.91 \\
16.24 \\
14.91 \\
14.85 \\
14.23 \\
13.56 \\
10.83 \\
5.90 \\
18.83\end{array}$ & $\begin{array}{r}12.77 \\
13.94 \\
13.85 \\
14.85 \\
13.72 \\
14.34 \\
13.48 \\
14.99 \\
14.32 \\
12.66 \\
13.18 \\
12.78 \\
12.22 \\
9.65 \\
5.54 \\
15.00\end{array}$ & $\begin{array}{r}42.76 \\
35.81 \\
33.26 \\
30.59 \\
30.59 \\
27.80 \\
27.80 \\
24.87 \\
21.79 \\
21.79 \\
18.57 \\
18.57 \\
15.20 \\
11.66 \\
7.96 \\
30.85\end{array}$ & $\begin{array}{r}41.40 \\
35.88 \\
33.88 \\
31.94 \\
31.17 \\
28.60 \\
28.62 \\
26.56 \\
24.06 \\
22.89 \\
20.24 \\
20.17 \\
16.81 \\
13.27 \\
9.18 \\
34.52\end{array}$ \\
\hline
\end{tabular}

Standard errors ranged from 0.21 to $0.32\left(R_{o}\right)$, and from 0.16 to $0.43\left(F_{o}\right)$.

Table III. Expected and observed cumulative selection response, $R_{E}$ and $R_{o}$, and inbreeding coefficient (\%), $F_{E}$ and $F_{o}$, after 5 generations of selection, as a function of family size. The initial additive variance was $50, h^{2}=0.30$.

\begin{tabular}{ccccc}
\hline Case & $R_{E}$ & $R_{o}$ & $F_{E}$ & $F_{o}$ \\
\hline 1 & 24.48 & 18.85 & 42.76 & 40.61 \\
2 & 26.17 & 20.17 & 35.81 & 35.06 \\
3 & 25.93 & 20.77 & 33.26 & 32.75 \\
4 & 26.03 & 20.38 & 30.59 & 31.77 \\
5 & 25.35 & 20.53 & 30.59 & 30.79 \\
6 & 25.45 & 20.84 & 27.80 & 28.48 \\
7 & 24.29 & 19.95 & 27.80 & 29.31 \\
8 & 25.21 & 20.42 & 24.87 & 26.26 \\
9 & 24.49 & 20.66 & 21.79 & 24.19 \\
10 & 22.27 & 18.86 & 21.79 & 21.74 \\
11 & 22.71 & 19.21 & 18.57 & 20.15 \\
12 & 21.89 & 18.86 & 18.57 & 20.47 \\
13 & 21.13 & 19.08 & 15.20 & 17.89 \\
14 & 17.51 & 16.28 & 11.66 & 13.44 \\
15 & 10.81 & 10.56 & 7.96 & 9.23 \\
Opt. & 27.64 & 21.09 & 28.71 & 31.92 \\
\hline
\end{tabular}

Standard errors ranged from 0.17 to $0.27\left(R_{o}\right)$, and from 0.16 to $0.43\left(F_{o}\right)$. 
The expected genetic progress, $R_{E}$, and inbreeding coefficient, $F_{E}$ are shown in Tables II and III. As is well known, within-family selection leads to a poor genetic progress but, as soon as the worst families are not allowed to reproduce, response quickly increases (cases 13 and 14), although none of the fifteen cases gives $R_{E}$, as large as that for $\lambda \geq 3$ in Table I. This is because selection acts independently on within- and between-family genetic variation in this strategy, and therefore, selection will be less efficient than with unrestricted family size.

As expected, $F_{E}$ decreased as the distribution of family size became more uniform. In case 8 , inbreeding was maintained below the maximum desired level, with a reduction in response of less than $10 \%$, with respect to the optimum.

The agreement between observed response $\left(R_{o}\right)$, obtained by genetic simulation, and expected results $\left(R_{E}\right)$ was better in those cases in which the variance of family size was small. In case 9 , the desired inbreeding is maintained, with a reduction in response of about $5 \%$, with respect to the optimum combined selection (lower row).

\section{Minimum coancestry matings}

The observed genetic progress attained during the first 5 generations of selection, both with random, $R_{R}$, and minimum coancestry matings, $R_{M C}$, together with the corresponding inbreeding coefficients, $F_{R}$ and $F_{M C}$, are shown in Table IV ( $\lambda_{o p}$ was used). The selection response obtained was similar in both cases, as expected in a strictly additive model. However, minimum coancestry matings dramatically reduced inbreeding, compared with random mating. Nevertheless, it should be noted that this reduction was mainly due the one generation delay in the initial appearance of consanguinity.

Table IV. Observed cumulative selection response after 5 generations of selection with random mating, $R_{R}$, minimum coancestry mating, $R_{M C}$, and mate selection, $R_{M S}$, together with their respective inbreeding coefficient $(\%) F_{R}, F_{M C}$ and $F_{M S}$. The initial additive variance was 50 .

\begin{tabular}{lrrrrrr}
\hline Generation & \multicolumn{1}{c}{$R_{R}$} & $R_{M C}$ & $R_{M S}$ & \multicolumn{1}{c}{$F_{R}$} & $F_{M C}$ & $F_{M S}$ \\
\hline$h^{2}=0.10$ & & & & & & \\
1 & 3.71 & 3.86 & 2.76 & 8.49 & 0.00 & 3.01 \\
2 & 6.58 & 6.53 & 5.74 & 15.89 & 8.54 & 7.87 \\
3 & 9.48 & 9.08 & 8.53 & 22.54 & 14.10 & 13.56 \\
4 & 12.27 & 11.98 & 11.64 & 28.88 & 19.08 & 18.73 \\
5 & 15.00 & 14.10 & 14.45 & 34.52 & 24.08 & 23.77 \\
$h^{2}=0.30$ & & & & & & \\
1 & 5.26 & 5.65 & 4.96 & 7.87 & 0.00 & 3.03 \\
2 & 9.54 & 9.64 & 9.90 & 14.44 & 7.21 & 8.00 \\
3 & 14.51 & 16.68 & 14.38 & 21.01 & 12.48 & 13.19 \\
4 & 17.43 & 17.79 & 18.49 & 26.43 & 17.03 & 17.81 \\
5 & 21.09 & 21.34 & 22.31 & 31.92 & 21.78 & 22.92 \\
\hline
\end{tabular}

Standard errors in the fifth generation ranged from 0.23 to $0.28\left(R_{R}\right.$ and $\left.R_{M C}\right), 0.80$ $\left(R_{M S}\right)$ and $0.40\left(F_{R}, F_{M C}\right.$ and $\left.F_{M S}\right)$. 


\section{Mates selection}

Table IV shows the observed response, $R_{M S}$, and the inbreeding coefficient, $F_{M S}$. It can be seen that, while conforming with inbreeding restrictions, response was not smaller than that attained under the optimum unrestricted scheme, $R_{R}$.

\section{DISCUSSION}

It is generally accepted (Hill, 1985; 1986) that the importance of population size in a selection program depends on the time horizon in which the breeder operates. If we are only interested in the first few generations, it matters little and selection should be as intense as possible. As the time horizon increases, larger population sizes will be needed in order to compensate for inbreeding depression and the loss of useful genes initially present in the population. Although the influence of a limited population size on selection response has been extensively studied (Hill, 1985; 1986), there are no general equations that can be used to predict either the inbreeding coefficient or cumulative response to selection in intermediate generations, and they would probably require information on the distribution of gene effects and frequencies that is not likely to be available. Recent results derived by Keightley and Hill (1987), Chevalet (1988) and Verrier et al (1988) could be of importance in this context.

Small herds are found in many situations and in some cases it has been increasingly popular to advocate the use of family information in their genetic evaluation; $e g$, in selection for prolificacy in pigs (Avalos and Smith, 1987), or MOET schemes in cattle and sheep (Smith, 1988a). Nevertheless, the inclusion of information from relatives has some undesirable consequences, as previously emphasized by Toro et al (1988b) and Dempfle (1988). First, discrepancies between theoretical and actual rates of responses steadily grow with the complexity of the family index utilized because of the increasingly correlated structure of the index values causing a lower than expected response. Second, the rate of inbreeding will be higher than that obtained with simpler methods, because the probability of selecting related individuals is higher. Additionally, the reduction of genetic variance due to generation of linkage disequilibrium, the so-called "Bulmer effect" (Bulmer, 1971), is greater when the accuracy of selection increases.

A reasonable proposal for these small herds is to maximize genetic progress, while imposing at the same time a restriction on the rate of inbreeding. Here, we have explored several possibilities of attaining this goal and have illustrated them with a simple example. The most obvious one (ie, to increase the proportion selected) is not an easy task if a balanced population structure is to maintained. A more flexible strategy is to reduce the weight given the family information and, as has been shown, a considerable reduction in inbreeding can be attained with little loss in response. In more complex situations, such as with BLUP evaluation, a deliberately overestimed heritability could be used in evaluating the animals, since the higher the heritability, the smaller the weight given to information from relatives. In this case, records should be first corrected for fixed effects using the appropriate parameters. The third strategy considered, imposes a restriction on the distribution of family size by fixing its variance. In the example, a distribution of 
family size (case 9) has been found that meets our objective, while maintaining the desired level of inbreeding and attaining an observed response of $95 \%$, with respect to the optimum. A drawback of this method is that, if the number of families is large and the number of selected males and females differ, it can become an extremely tedious task to find the optimum situation. In practice, another shortcoming could arise since the number of selected offspring left by each family cannot always be completely controlled. An additional advantage of these "within-family" selection methods is the slower decrease of the genetic variance, as shown by Dempfle (1975) for classical within-family selection and, therefore, the long-term response will be expected to increase.

Another course of action that can be taken, is to practice minimum coancestry matings. This is especially valuable when family index selection is used. Since an important fraction of the inbreeding reduction arises from the delay in the appearance of consanguineous matings, its usefulness will be greater in the short term, whereas, in the long term, its effectiveness may well be reduced. Anyway, a substantial reduction in the final inbreeding was attained in our 5 generation example.

Finally, the use of integer linear programing can provide a general solution for the selection and mating policy, regardless of population structure, evaluation method, or selection intensity, as previously suggested by Jansen and Wilton (1984), Smith and Allaire (1985) and Kinghorn (1987). In this context, genetic evaluation should be made using the best available technique, namely, the animal model, and individuals and matings should be chosen to conform to the inbreeding restriction. Unfortunately, both processes are very demanding from the computation point of view and, in pratice, similar results can probably be obtained using some of the simpler methods outlined. The results that can be obtained with integer programing depend critically on $\Delta F$, the restriction on inbreeding imposed in a specific program. Thus, if $\Delta F$ is large, only the best animals (regardless of their genetic relationship) will be chosen, and the results will not differ from those obtained with conventional, random-mating systems. On the contrary, if $\Delta F$ is kept at a very low value, the less related animals (which are not necessarily the best) would to be selected. This case would be similar to that of minimum coancestry mating (among the preselected best-half animals). The advantage of the general strategy, therefore, is expected to be greater at intermediate values of $\Delta F$. In practice, breeders design the structure of the population in order to maintain the rate of inbreeding below the desired level. For example, Smith (1988b) has suggested that the size of a MOET nucleus unit should be such that the level of inbreeding is similar to that attained in a national program ( 0.005 per year).

In some situations, it can be argued that the aim of a selection program should be to increase the accumulated selection response up to a fixed time, regardless of the inbreeding coefficient, because those lines will eventually enter a program of regular crossing. The most appropriate course of action in such cases would be to estimate a value of $N_{e}$, giving the maximum response in a fixed number of generations, and subsequently to apply some of the outlined strategies. 


\section{ACKNOWLEDGMENTS}

We are indebted to C López-Fanjul, L Silió, A García-Dorado, A Gallego and A Caballero for very helpful comments. We are also grateful to the staff of Sección de Proceso de Datos of the INIA for their kind cooperation. This work has been supported by a CICYT grant.

\section{REFERENCES}

Avalos E, Smith C (1987) Genetic improvement of litter size in pigs. Anim Prod 44, 153-163

Bulmer MG (1971) The effect of selection on genetic variability. Am Nat 105, 201211

Burrows PM (1984) Inbreeding under selection from unrelated families. Biometrics 40, 357-366

Butler I von, Willeke H, Pirchner F (1984) Two-way within-family and mass selection for 8-week body weight in different mouse populations. Genet Res 43, 191-200

Chevalet C (1988) Control of genetic drift in selected populations. In: Proc 2nd Int Conf in Quantitative Genetics, Sinauer, Sunderland, USA (Weir BS, Eisen EJ, Goodman NM, Namkoong G, eds), 379-394

Crow JF; Kimura M (1970) An Introduction to Population Genetics Theory. Harper \& Row, New York, p 103

Crow JF, Denniston C (1988) Inbreeding and variance effective population numbers. Evolution 42, 482-495

Dempfle L (1975) A note on increasing the limit of selection through selection within families. Genet Res 24, 127-135

Dempfle L (1988) Design of experiments and of breeding programms. Int Sym on Advances in Statistical Methods for Genetic Improvement of Livestock, Armidale

Ducrocq V, Colleau JJ (1986) Interest in quantitative genetics of Dutt's and Deak's methods for numerical computation of multivariate normal probability integrals. Gent Sel Evol 18, 447-474

Falconer DS (1981) Introduction to Quantitative Genetics. Longmans, London 2nd edn, p 213

Frankham R (1977) Optimum selection intensities in artificial programmes: an experimental evaluation. Genet Res 30, 115-119

Gallego A, López-Fanjul C (1983) The number of loci affecting a quantitative trait in Drosophila melanogaster revealed by artificial selection. Gent Res 42, 137-149

Gupta SS (1963) Probability integrals of multivariate normal and multivariate $t$. Ann Math Statist 34, 792-828 
Hill WG (1976) Order statistics of correlated variables and implications in genetic selection programmes. Biometrics 32, 889-902

Hill WG (1985) Effects of population size on response to short and long term selection. J Anim Breed Genet 102, 161-173

Hill WG (1986) Population size and design of breeding programmes. In: Proc 3rd World Congress Applied to Livestock Production, 16-22 July, Lincoln, Nebraska, Vol 9, 245-256

Jansen GB, Wilton JW (1984) Linear programming in selection of livestock. J Dairy Sci 67, 897-901

Keightley PD, Hill WG (1987) Directional selection and variation in finite populations. Genetics 117, 573-582

Kinghorn B (1987) On computing strategies for mate allocation. J Anim Breed Genet 104, 12-22

Land AH, Powell S (1973) Fortran Codes for Mathematical Programing: Linear, Quadratic and Discrete. John Wiley, London

Land R (1985) Knowledge for animal breeding. Phil Trans $R$ Soc London B 310, 243-280

Owen DB (1962) Handbook of Statistical Tables. Addison-Wesley, Reading, MA

Owen DB, Steck GP (1962) Moments of order statistics from the equicorrelated multivariate normal distribution. Ann Math Statist 33, 1286-1291

Robertson A (1960) A theory of limits in artificial selection. Proc $R$ Soc London B 153, 234-249

Robertson A (1961) Inbreeding in artificial selection programmes. Genet Res 2, 189-194

Robertson A (1970) Some optimum problems in individual selection. Theor Pop Biol 1, 120-127

Ruano RG, Orozco F, López-Fanjul C (1975) The effect of different selection intensities on selection response in egg-laying of Tribolium castanuem. Genet Res $36,117-131$

Smith C (1969) Optimum selection procedures in animal breeding. Anim Prod 11, 433-442

Smith C (1988a) Applications of embryo transfer in animal breeding. Theriogenology $29,203-212$

Smith C (1988b) Checking rates of genetic response with new reproductive techniques. In: Proc. 3rd World Congress on Sheep and Beef Cattle Breeding, Paris, 19-23 June, Vol 1, 159-171

Smith SP, Allaire FR (1985) Efficient rules to increase non-linear merit: application in mate selection. Genet Sel Evol 17, 387-406

Toro MA, Nieto B (1984) A simple method for increasing the response to selection. Genet Res 44, 347-349 
Toro MA, Nieto B, Salgado C (1988a) A note on miminization of inbreeding in small-scale selection programmes. Livestock Prod Sci 20, 317-323

Toro MA, Silió L, Rodrigánez J, Dobao MT (1988b) Inbreeding and family index selection for prolificacy in pigs. Anim Prod 46, 79-85

Verrier E, Colleau JJ, Foulley JL, Ducroq V (1988) Predicting the additive genetic variance in finite populations undergoing mass selection. ADSA 83rd Annual Meeting, 26-29 June, Edmonton, Alberta 